\title{
Inhibition of autophagy by 3-methyladenine potentiates sulforaphane-induced cell death of BE(2)-C human neuroblastoma cells
}

\author{
IRENA HORWACIK $^{1 *}$, MONIKA GAIK ${ }^{1,4^{*}}$, MAŁGORZATA DURBAS ${ }^{1}$, ELŻBIETA BORATYN $^{1}$, \\ GRZEGORZ ZAJĄC ${ }^{1}$, KATARZYNA SZYCHOWSKA ${ }^{1}$, MAŁGORZATA SZCZODRAK ${ }^{2}$, \\ HENRYK KOŁOCZEK ${ }^{3}$ and HANNA ROKITA ${ }^{1}$
}

\author{
${ }^{1}$ Faculty of Biochemistry, Biophysics and Biotechnology, Jagiellonian University, Kraków 30-387; ${ }^{2}$ Department of Biochemistry, \\ University of Agriculture, Kraków 31-425; ${ }^{3}$ Department of Inorganic Technology and Environmental Biotechnology, \\ Cracow University of Technology, Kraków 31-155, Poland
}

Received March 31, 2014; Accepted November 20, 2014

DOI: $10.3892 / \mathrm{mmr} .2015 .3377$

\begin{abstract}
Sulforaphane (SFN) is an isothiocyanate present in cruciferous vegetables, which has been shown to exert an anti-cancer effect when tested in vitro and in vivo. The anti-cancer effects of SFN encompass induction of cytoprotective autophagy; therefore, the present study aimed to determine whether the chemopreventive activity of SFN may be potentiated by inhibition of autophagy. The present study provided detailed insight into the susceptibility of human neuroblastoma cells to treatment with synthetic SFN, in combination with an inhibitor of autophagy, 3-methyladenine (3-MA). The present study confirmed the suppression of the viability of the human neuroblastoma cell line BE(2)-C by SFN and reported the inhibition of DNA synthesis, as determined by a decrease in tritiated thymidine incorporation. Furthermore, the results verified the effectiveness of SFN in inducing apoptosis in the BE(2)-C cell line as demonstrated by caspase activation, increased protein expression levels of B-cell lymphoma 2-associated X protein and loss of mitochondrial membrane potential. Combined treatment of the cells with SFN with 3-MA proved to be effective in decreasing cell viability, through a mechanism that may proceed via the early induction of autophagy by SFN, followed by induction of apoptosis, as well as inhibition of autophagy by 3-MA.
\end{abstract}

Correspondence to: Professor Hanna Rokita, Faculty of Biochemistry, Biophysics and Biotechnology, Jagiellonian University, 7 Gronostajowa Street, Kraków 30-387, Poland E-mail: hanna.rokita@uj.edu.pl

Present address: ${ }^{4}$ Biochemistry Center (BZH), Heidelberg University, Heidelberg 69120, Germany

*Contributed equally

Key words: sulforaphane, 3-methyladenine, neuroblastoma, autophagy, apoptosis

\section{Introduction}

Sulforaphane, [1-isothiocyanato-4-(methylsulfinyl)-butane; $(\mathrm{SFN})]$ is an isothiocyanate compound found in cruciferous vegetables, including broccoli and cauliflower. SFN is a well-known cancer chemopreventive agent, which may also influence normal cells (1). Two putative mechanisms of action underlying the anti-cancer effect of isothiocyanates have been identified. The first mechanism is based on the activation of the phase 2 detoxification enzymes, such as glutathione S-transferase, and/or the simultaneous inhibition of the phase 1 enzymes, such as cytochrome $\mathrm{P} 450$ isoenzyme 2E1, which may be responsible for the anti-carcinogenic activity $(2,3)$. Upregulation of phase 2 enzymes, including glutathione transferases, protects cells against carcinogens and has previously been shown to prevent carcinogen-induced tumors in various animal models $(1,2,4)$. The second mechanism refers to the suppression of tumor development by the induction of apoptosis, growth inhibition and cell cycle arrest (5-8). At the molecular level, the protective properties of SFN rely on activation of the pro-apoptotic B-cell lymphoma 2 (Bcl-2)-associated X protein (Bax), resulting in apoptosis of endothelial progenitor cells and consequently reducing tumor growth (9). In addition, SFN has been shown to inhibit histone deacetylase activity and cause histone hyperacetylation in cancer cells, including human colon cancer (10).

The induction of apoptosis by SFN has previously been observed in numerous cancer models, including the prostate cancer cell lines PC-3 and LNCaP (8) and the human colon cancer cell line HT29 (5). However, the exact mechanism underlying the induction of apoptosis by SFN remains to be elucidated. SFN-induced apoptosis in human prostate cancer cell lines was shown to be initiated by the production of reactive oxygen species (ROS) $(7,11)$. In addition, caspase 8 is associated with SFN-induced apoptosis and its activity depends on ROS production (7).

SFN was previously reported to induce autophagy in prostate cancer cell lines, which provided protection against the induction of apoptosis by SFN (8). The physiological 
function of autophagy is to maintain a natural balance between existing and forthcoming synthesized proteins and organelles. Autophagy literally means 'self-eating' and is a process of cellular self-digestion which may lead to cell death (12). The process of digesting organelles and molecules occurs in double-membrane autophagosomes (13). The protein beclin-1 interacts with a class III phosphatidyl-inositol 3-kinase (PI3K) and initiates autophagosomal membrane assembly (14). Furthermore, microtubule-associated protein light chain 3 (MAP-LC3 or LC3) is incorporated into the autophagosome membrane, which may be tracked until fusion with the lysosome vesicle (15). MAP-LC3 exists in two forms: cytoplasmic LC3-I (18 kDa) and autophagosome-associated LC3-II (16 kDa), which has undergone proteolytic cleavage (16). In the PC-3 prostate cancer cell line, SFN causes redistribution of LC3 into autophagosomes and 3-methyladenine (3-MA), an inhibitor of autophagy, is able to restrain this process (8). The adenine analogue blocks class III PI3K complex activities and the mammalian target of rapamycin pathway, leading to the inhibition of autophagy (17).

The present study used the $\mathrm{BE}(2)-\mathrm{C}$ human neuroblastoma cell line containing the amplified $M Y C N$ gene (responsible for high levels of aggressiveness) and P53 mutation, to characterize the effects of synthetic SFN on cells in vitro. The effects of SFN on caspase activity, the mitochondrial membrane potential and Bax levels were also investigated. The results of the present study confirmed the effectiveness of SFN in the induction of apoptosis in the $\mathrm{BE}(2)-\mathrm{C}$ cell line as well as its ability to induce early autophagy. The present study showed that the combined treatment of the cells with SFN with 3-MA enhanced cell death.

\section{Materials and methods}

Reagents. D,L-Sulforaphane was synthesized at the University of Agriculture (Kraków, Poland), according to the method by Schmidt and Karrer (18). Purification of the compound was performed by high-performance liquid chromatography and the identity of the SFN was verified by nuclear magnetic resonance and ultraviolet spectroscopy. A stock solution of SFN (7.2 $\mathrm{M}$ in serum-free medium) was stored at $-20^{\circ} \mathrm{C}$ until further use. SFN was diluted with culture medium immediately prior to use. 3-MA, staurosporine (STS) and antibodies against GAPDH (G8795) were purchased from Sigma-Aldrich (Poznań, Poland). Trypsin (0.25\%) was obtained from Gibco Life Technologies (Carlsbad, CA, USA), and $\left(6-{ }^{3} \mathrm{H}\right)$ thymidine was from GE Healthcare Life Sciences (Little Chalfont, UK). Rabbit antibodies against LC3B (3868) and beclin-1 (3495) were purchased from Cell Signaling Technology (Danvers, MA, USA). An antibody against Bcl-2 (sc-783) was obtained from Santa Cruz Biotechnology (Dallas, TX, USA) and an antibody against Bax (556467) was obtained from BD Pharmingen (San Diego, CA, USA). Secondary horseradish peroxidase (HRP)-conjugated goat anti-rabbit immunoglobulin G ( $\mathrm{IgG}$ ) (A0545) and anti-mouse IgG antibodies (A9044) were obtained from Sigma-Aldrich. The secondary anti-rabbit IgG HRP-linked antibodies (7074) were from Cell Signaling Technology. All of the other chemicals and reagents used in the experiments of the present study were of analytical grade.
Cell culture. The BE(2)-C human neuroblastoma cell line was obtained from the American Type Culture Collection (Manassas, VA, USA; ATCC number, CRL-2268). The $\mathrm{BE}(2)-\mathrm{C}$ cell line is a clone of the $\mathrm{SK}-\mathrm{N}-\mathrm{BE}(2)$ neuroblastoma cell line. The cells were cultured in a 1:1 mixture of Eagle's minimum essential medium and F12 medium, supplemented with $10 \%$ fetal calf serum, $1 \%$ non-essential amino acid solution, $1 \mathrm{mM}$ sodium pyruvate and $50 \mu \mathrm{g} / \mathrm{ml}$ gentamicin (all from Sigma Aldrich) at $37^{\circ} \mathrm{C}$ in an atmosphere containing $5 \% \mathrm{CO}_{2}$.

MTT assay. The MTT assay is based on the ability of living cells to reduce the MTT tetrazolium salt to MTT formazan by the mitochondrial enzyme succinate dehydrogenase (19). The BE(2)-C cells (2.5x10\%/well) were cultured in 96-well plates for $24 \mathrm{~h}$ and treated with increasing concentrations of synthetic SFN for the indicated time periods. MTT (Sigma-Aldrich) was added to each well to a final concentration of $0.5 \mathrm{mg} / \mathrm{ml}$. Following a 4 -h incubation at $37^{\circ} \mathrm{C}$, the formazan crystals were dissolved in isopropanol containing $5 \mathrm{mM} \mathrm{HCl}$. The absorbance was measured at wavelengths of 570 and $630 \mathrm{~nm}$ using the SpectraMax 250 microplate reader (Molecular Devices, Sunnyvale, CA, USA). The 50\% maximal inhibitory concentration $\left(\mathrm{IC}_{50}\right)$ was defined as the concentration that resulted in a $50 \%$ decrease in the absorbance of the SFN-treated cells, as compared with the media-grown cells. In separate experiments, the $\mathrm{BE}(2)-\mathrm{C}$ cells $\left(2.5 \times 10^{4} /\right.$ well $)$ were cultured in 96-well plates for $24 \mathrm{~h}$. The medium was then removed and the cells were treated with either $40 \mu \mathrm{M}$ synthetic SFN, $10 \mathrm{mM} 3-\mathrm{MA}$ or a combination of $40 \mu \mathrm{M}$ synthetic SFN and $10 \mathrm{mM}$ 3-MA. Untreated control cells were also included in the experiments. After $48 \mathrm{~h}$, the MTT assay was performed on the cells, as described above. The measurements were run in triplicate and the experiments were repeated three times.

Lactate dehydrogenase ( $L D H)$ activity measurement. The $\mathrm{BE}(2)-\mathrm{C}$ cells $\left(2.5 \times 10^{4} /\right.$ well) were cultured in 96 -well plates for $24 \mathrm{~h}$. The medium was then removed and the cells were treated with either $40 \mu \mathrm{M}$ synthetic SFN, $10 \mathrm{mM} 3-\mathrm{MA}$ or a combination of $40 \mu \mathrm{M}$ synthetic SFN and $10 \mathrm{mM}$ 3-MA. Untreated control cells were also included in the experiments. After $48 \mathrm{~h}$, the cell cultures were centrifuged at $250 \mathrm{x} \mathrm{g}$ for $10 \mathrm{~min}$ at room temperature. The medium was removed and the cells were lysed using 1\% Triton-X 100 (Sigma-Aldrich) in serum-free culture medium. LDH activity was measured using the Cytotoxicity Detecion kit (LDH) from Roche Diagnostics (Warsaw, Poland) according to the manufacturer's instructions. The measurements were run in triplicate and the experiments were repeated three times.

Crystal violet staining. The $\mathrm{BE}(2)-\mathrm{C}$ cells $\left(2.5 \times 10^{4} /\right.$ well $)$ were cultured in 96-well plates for $24 \mathrm{~h}$. The medium was then removed and the cells were treated with either $40 \mu \mathrm{M}$ synthetic SFN, $10 \mathrm{mM} 3$-MA or a combination of $40 \mu \mathrm{M}$ synthetic SFN and $10 \mathrm{mM}$ 3-MA. Untreated control cells were also included in the experiments. After $48 \mathrm{~h}$, the cells were collected and centrifuged at $250 \mathrm{xg}$ for $10 \mathrm{~min}$ at room temperature. The culture medium was then removed, the cells were fixed with $0.1 \%$ crystal violet (Sigma-Aldrich) in $20 \%$ ethanol (Sigma-Aldrich) for $10 \mathrm{~min}$ and washed once with distilled 
water. The cells were observed using a Nikon Eclipse TS100 microscope (Nikon Corooration, Tokyo, Japan). Images of the cells were captured using a digital camera (Canon Powershot A1200; Canon, Inc., Tokyo, Japan).

Thymidine incorporation. A thymidine incorporation assay was performed in order to measure the rate of DNA synthesis. The BE(2)-C cells were seeded in a 24-well plate $\left(1.6 \times 10^{5}\right.$ cells/well) and allowed to attach. After $24 \mathrm{~h}$ the medium was refreshed and the indicated concentrations of SFN (10-100 $\mu \mathrm{M})$ were added. The cells treated with media alone were used as control cells. Following a 24-h incubation, the media was replaced with $400 \mu 1$ isotope solution (activity, $1 \mu \mathrm{Curie} / \mathrm{ml}$ ). The samples were prepared according to the methods by Riss and Sirbasku (20). After $24 \mathrm{~h}$, the cells were fixed with $800 \mu \mathrm{l}$ cold $\left(4^{\circ} \mathrm{C}\right)$ methanol-acetic acid solution (3:1 proportion; $\mathrm{POCH}$, Gliwice, Poland). The solution was then aspirated and each well was washed with $80 \%$ methanol and dried for $30 \mathrm{~min}$ at room temperature. A total of $125 \mu 1$ trypsin was added to each well and incubated for $30 \mathrm{~min}$ at $37^{\circ} \mathrm{C}$. Following incubation, $125 \mu 11 \% \mathrm{SDS}$ solution (Sigma-Aldrich) was added and plates were incubated for $30 \mathrm{~min}$ at $25^{\circ} \mathrm{C}$. Finally, $20 \mu \mathrm{l}$ of each sample was mixed with $3 \mathrm{ml}$ scintillator carrier (Akwascynt, POCH). The measurements were performed using the 1211 Rackbeta Liquid Scintillation Counter (LKB Wallac; LKB Instruments, Victoria, Australia). Four cycles of measurements were performed and the first measurement was discarded. The results are presented as plots of counts per minute for $1 \mu \mathrm{g}$ of whole-cell protein content. The protein concentration was determined using the bicinchoninic acid assay, according to the manufacturer's instructions (Sigma-Aldrich). The measurements were run in triplicate and the experiment was repeated three times.

Caspase activation assay. The activation of caspases 2, 3, 6, 7, 8, 9 and 10 was determined using the Homogeneous Caspases Assay (Roche Diagnostics) according to the manufacturer's instructions. The $\mathrm{BE}(2)-\mathrm{C}$ cells $\left(4 \times 10^{4}\right)$ were seeded onto 96-well plates with black sides and a transparent, flat bottom (Corning-Costar, Corning, NY, USA), and allowed to attach. Following a 24-h incubation, the medium was replaced and the cells were treated with either the medium alone (control) or the indicated concentrations of SFN and/or 3-MA for the indicated periods of time. The samples were tested in duplicate, the fluorescent signals were measured using the Infinite ${ }^{\circledR} 200$ PRO multimode reader (Tecan Group Ltd, Maennedorf, Switzerland).

Immunoblotting. The $\mathrm{BE}(2)-\mathrm{C}$ cells $\left(1 \times 10^{6}\right)$ were grown on 55-mm diameter plates and treated with SFN and/or 3-MA, as described above. Whole cell extracts were obtained according to the methods of Sadowski et al (21). Briefly, following the indicated period of incubation, the media was removed and the cells were collected in cold phosphate-buffered saline (PBS), then washed with PBS and centrifuged at $140 \mathrm{x}$ g for $5 \mathrm{~min}$ at $4^{\circ} \mathrm{C}$. The samples were then resuspended in 70-100 $\mu 1$ lysis buffer $(50 \mathrm{mM}$ Tris-HCl, pH 8.0, $10 \mathrm{mM}$ 3-[(3-cholamidopropyl) dimethylammonio]-1-propanesulfonate, $2 \mathrm{mM}$ EDTA, $1 \mathrm{mM} \mathrm{Na}_{3} \mathrm{VO}_{4}, 5 \mathrm{mM} \mathrm{NaF}, 1 \mathrm{mM}$ dithiothreitol, $1 \mathrm{mM}$ phenylmethanesulfonylfluoride; $10 \%$ glycerol) and incubated on ice for $20 \mathrm{~min}$. All reagents were purchased from BioShop Canada, Inc., (Burlington, ON, Canada). The lysates were aspirated through a syringe (0.6-mm diameter) and centrifuged at $11,400 \mathrm{x}$ g for $5 \mathrm{~min}$ at $4^{\circ} \mathrm{C}$. The supernatants were collected and stored at $-20^{\circ} \mathrm{C}$ until further use. The protein lysates were separated by SDS-PAGE and transferred onto polyvinylidene difluoride membranes (Hybond P; Merck Millipore, Warsaw, Poland). The membranes were treated with a solution containing $10 \mathrm{mM}$ Tris ( $\mathrm{pH} 7.4$; BioShop Canada), $150 \mathrm{mM} \mathrm{NaCl}$ (POCH), 0.05\% Tween ${ }^{\circledR} 20$ (Sigma-Aldrich) and 5\% nonfat dry milk (Cell Signalling Technology, Inc.) and incubated with the desired primary antibody for $1 \mathrm{~h}$ at room temperature. Antibodies, raised against human antigens, included rabbit monoclonal anti-beclin-1 antibody $(1: 1,000)$ and rabbit monoclonal anti-LC3B antibody (1:1,000), from Cell Signaling Technology, Inc. Rabbit polyclonal anti-Bcl-2 antibody (DC 21, 1:1,000; sc-783) and mouse monoclonal anti-Bax antibody (B-9, 1:1,000; sc-7480) from Santa Cruz Biotechnology, Inc. and mouse monoclonal anti-GAPDH antibody G8795 (1:40,000) from Sigma-Aldrich. Following incubation with these primary antibodies, the membranes were washed three times for $5 \mathrm{~min}$ with the solution containing $10 \mathrm{mM}$ Tris (pH 7.4), $150 \mathrm{mM} \mathrm{NaCl}$ with $0.1 \%$ Tween ${ }^{\circledR} 20$. After the washing steps, the membranes were treated with the appropriate HRP-conjugated secondary antibodies for $1 \mathrm{~h}$ at room temperature. The secondary antibodies with indicated dilutions were as follows: rabbit anti-mouse IgG-HRP, A9044, 1:50,000 (Sigma-Aldrich); goat anti-rabbit IgG-HRP, A0545, 1:20,000 (Sigma-Aldrich); goat anti-rabbit IgG-HRP, \#7074, 1:2,000 (Cell Signaling Technology). After secondary antibodies incubation, membranes were washed as described above. The immunoreactive bands were visualized using an Enhanced Chemiluminescence substrate (Immobilon Western HRP substrate; Merck Millipore), according to the manufacturer's instructions. The intensity of the immunoreactive bands was determined by densitometric scanning in order to quantify the changes to the protein expression levels (Quest Spot Cutter, Quantity One, version 4.6.9 software; Bio-Rad Laboratories, Hercules, CA, USA). The experiment was repeated between two and four times and representative results are shown.

Flow cytometric analysis of the mitochondrial membrane potential. To measure the mitochondrial membrane potential $\left(\Delta \psi_{\mathrm{m}}\right)$ in the neuroblastoma cells, flow cytometric analyses were performed using the MitoTracker ${ }^{\circledR}$ Red CMXRos dye (Invitrogen Life Technologies, Carlsbad, CA, USA). The cells were plated and treated as described above. Cells treated with $60 \mu \mathrm{M}$ STS, an unspecific protein kinase inhibitor, were used as a positive control. The CMXRos staining protocol was performed as follows. The $\mathrm{BE}(2)-\mathrm{C}$ cells were collected, centrifuged at $250 \mathrm{x}$ g for $10 \mathrm{~min}$ at $4^{\circ} \mathrm{C}$ and stained with $1 \mathrm{ml} 500 \mathrm{nM}$ CMXRos solution per $1 \mathrm{ml}$ cell suspension [in medium with $10 \%$ fetal bovine serum (FBS), $15 \mathrm{~min}, 37^{\circ} \mathrm{C}$ ]. The cells were then washed twice with media supplemented with $2 \%$ FBS and resuspended in $0.5 \mathrm{ml}$ media. The cells were analyzed using a FACScan (BD Biosciences, Franklin Lakes, NJ, USA). The experiment was repeated three times.

Statistical analysis. Values are presented as the means. Error bars of the means in Figs. $1 \mathrm{~B}$ and $\mathrm{C}$ and 2A were calculated 
according to the law of propagation of uncertainty. Otherwise, the error bars denote the standard error of the mean. Experiments were repeated between two and four times. A series of pairwise tests (t-test) comparing the differences between the means of the groups, were also performed. This was calculated using Microsoft Office Excel 2003; Microsoft Corporation, Redmond, WA, USA). $\mathrm{P}<0.05$ was considered to indicate a statistically significant difference $\left({ }^{*} \mathrm{P}<0.05 ;{ }^{* *} \mathrm{P}<0.01 ;{ }^{* * *} \mathrm{P}<0.001\right)$.

\section{Results}

SFN-induced inhibition of the growth of BE(2)-C cells. In order to determine the inhibitory influence of SFN on the BE(2)-C neuroblastoma cell line, the cells were cultured with increasing concentrations of the synthetic isothiocyanate $(5-100 \mu \mathrm{M})$ for 24 and $48 \mathrm{~h}$. Untreated cells were also included. The $\mathrm{IC}_{50}$-value after $24 \mathrm{~h}$ was calculated as $38 \mu \mathrm{M}$ (data not shown). Therefore, based on earlier assays and previously published results $(8,22)$, $40 \mu \mathrm{M}$ SFN was subsequently selected for further experiments. Microscopic evaluation (data not shown) and crystal violet staining of the SFN-treated cells suggested that SFN treatment caused cell death and after $48 \mathrm{~h}$, the cells began to detach from the culture dish (Fig. 1A). Combinatorial treatment of the cells with SFN with 3-MA resulted in a marked detachment of cultured cells. Treatment with 3-MA alone did not alter the morphology of the cells. To assess the cytotoxicity of SFN on the cells, the cell viability was analyzed using an MTT assay (Fig. 1B). The inhibitory effects of SFN were clearly visible at $48 \mathrm{~h}$. Treatment of the BE(2)-C cells with $40 \mu \mathrm{M} \mathrm{SFN}$ also resulted in decreased cellular levels of $\mathrm{LDH}$, a cytosolic enzyme that leaks from damaged cells (Fig. 1C). Treatment with 3-MA slightly decreased the viability of the cells, as estimated by MTT assay, crystal violet staining and analysis of LDH activity (Fig. 1). However, the combined treatment with SFN and 3-MA resulted in a statistically significant decrease in the cellular parameters measured as compared with SFN treatment alone (Fig. $1 \mathrm{~B}$ and $\mathrm{C} ; \mathrm{P}<0.05$ and $\mathrm{P}<0.01$, respectively).

Purified broccoli sprout extracts containing $~ 90 \%$ SFN, used in our preliminary studies, have also shown potent inhibitory effects on the growth of numerous human cancer cell lines, including BE(2)-C neuroblastoma, HepG2 hepatoma and SK-MEL-28 melanoma (data not shown).

SFN induces caspase activation and decreases DNA content in neuroblastoma cells. To investigate whether apoptosis may be responsible for the decreased survival of the $\mathrm{BE}(2)-\mathrm{C}$ cells treated with SFN, total activity of caspases 2, 3, 6, 7, 8, 9 and 10 was assayed. The cells $\left(4 \times 10^{4}\right.$ per well) were cultured in the presence of $40 \mu \mathrm{M}$ SFN for $48 \mathrm{~h}$. Treatment with SFN resulted in a significant $\sim 1.5$-fold increase in the total activity of caspases 2, 3, 6, 7, 8, 9, and 10 (Fig. 2A; P<0.05) compared with the control cells. Furthermore, treatment with autophagy inhibitor 3-MA (10 mM) increased caspase activity when used alone (Fig. 2A). This effect was expected, as the inhibition of autophagy may be associated with increased apoptotic cell death (23). However, treatment with a combination of 3-MA and $40 \mu \mathrm{M}$ SFN resulted in a significant decrease in caspase activity, possibly due to prolonged incubation with high doses of SFN and 3-MA (Fig. 2A; P<0.01), compared with the control cells and to single agents treatments. As the exact types of
A

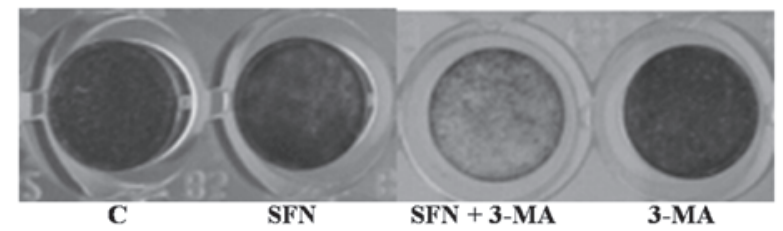

B

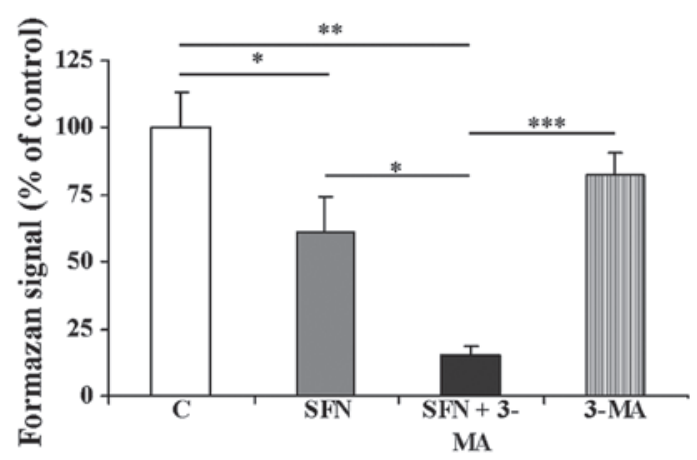

C

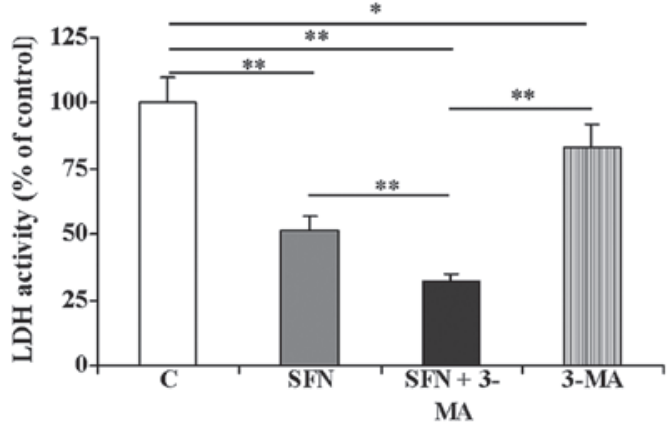

Figure 1. Effects of SFN on the viability of the BE(2)-C neuroblastoma cell line. The BE(2)-C cell cultures were treated for $48 \mathrm{~h}$ with $40 \mu \mathrm{M} \mathrm{SFN}$, $10 \mathrm{mM} 3$-MA or $40 \mu \mathrm{M}$ SFN in combination with $10 \mathrm{mM}$ 3-MA. (A) Crystal violet staining of the cells. (B) Results of the MTT assay are shown as a percentage of the untreated control. (C) LDH activity was measured in the cell cultures following removal of the medium and shown as a percentage of the control. (B and C) Values are presented as the means of triplicates, with the error bars calculated according to the law of propagation of uncertainty. One representative experiment of three independent experiments is shown. A series of pairwise t-tests were performed to compare the mean values of the treated cells, vs. control cells, and the single, vs. combined treatment groups. ${ }^{*} \mathrm{P}<0.05 ;{ }^{* *} \mathrm{P}<0.01 ;{ }^{* * *} \mathrm{P}<0.001$. LDH, lactate dehydrogenase; SFN, sulforaphane; 3-MA, 3-methyladenine; C, untreated control.

caspases involved in the process cannot be distinguished by the test used in the present study, it is possible that caspases of the receptor and mitochondrial pathways are involved in SFN-induced apoptosis (7).

The higher concentrations of SFN also inhibited DNA synthesis. The effects of SFN on its ability to repress ${ }^{3} \mathrm{H}$-thymidine incorporation into DNA were studied at four different concentrations $(10,50,75$ and $100 \mu \mathrm{M})$. The rate of ${ }^{3} \mathrm{H}$-thymidine incorporation decreased significantly with increasing SFN concentration (Fig. 2B; P<0.001) compared with the control cells. This result is concordant with previous findings reported by Rajendran et al (10), which showed that SFN may cause a severe decrease in DNA content in HCT116 cells treated with $15 \mu \mathrm{M}$ SFN for $24 \mathrm{~h}$.

Analysis of LC3 protein modification. To investigate whether autophagy may be induced by SFN treatment in the 
A

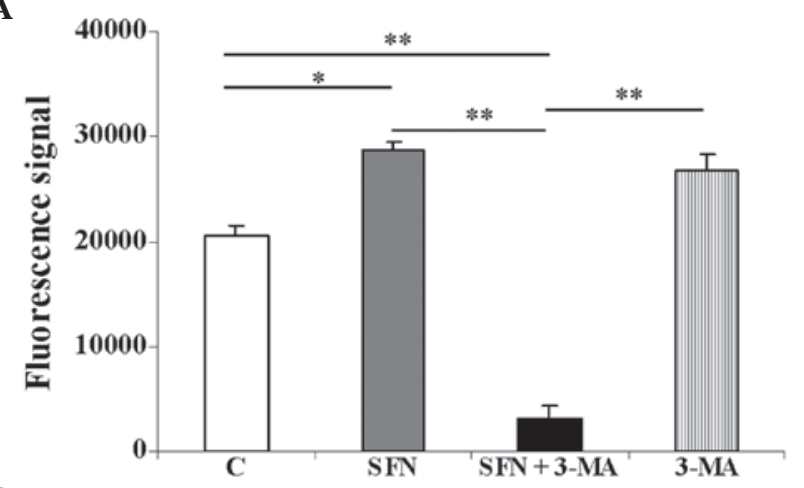

B

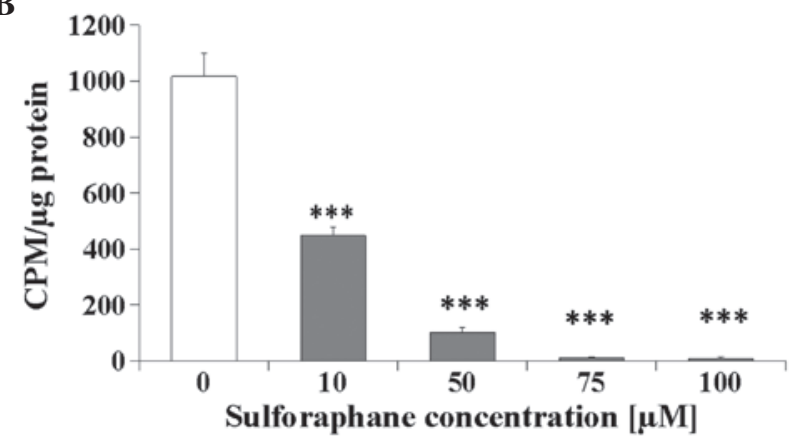

Figure 2. Caspase activity and DNA synthesis in the BE(2)-C neuroblastoma cells treated with SFN and 3-MA. The BE(2)-C cell cultures were treated with $40 \mu \mathrm{M}$ SFN, $10 \mathrm{mM}$ 3-MA or $40 \mu \mathrm{M}$ SFN in combination with $10 \mathrm{mM} 3$-MA. (A) After treatment for $48 \mathrm{~h}$, caspase activity was measured in the cellular extracts. Values are presented as the means from duplicated experiments, with error bars calculated according to the law of propagation of uncertainty. One representative experiment of three independent experiments is shown. A series of pairwise t-tests were performed to compare the mean values for the treated, vs. control cells; and the single, vs. combined treatment groups. (B) Results of ${ }^{3} \mathrm{H}$-thymidyne incorporation assay. A total of $1 \mu \mathrm{Curie} / \mathrm{ml}^{3} \mathrm{H}$-thymidine was added for $24 \mathrm{~h}$ following SFN treatment for $24 \mathrm{~h}$. The results are shown as CPMs per $\mu \mathrm{g}$ of total cellular protein. Values are expressed as the mean \pm standard error of the mean. A series of pairwise $\mathrm{t}$-tests, comparing the means of the treated, vs. control cells was performed. ${ }^{*} \mathrm{P}<0.05 ;{ }^{* *} \mathrm{P}<0.01 ;{ }^{* * *} \mathrm{P}<0.001$. SFN, sulforaphane; CPM, counts per minute; 3-MA, 3-methyladenine; C, untreated control.

$\mathrm{BE}(2)-\mathrm{C}$ cells, the proteolytic process of MAP LC3 (in short LC3) was assessed. The conversion from the endogenous, cytosolic LC3-I protein to the LC3-II protein, which binds to autophagosomal membranes, was detected by immunoblotting with antibodies against LC3 $(13,15)$. These results may provide evidence of early autophagy induction. The cells were treated with $40 \mu \mathrm{M}$ SFN, $10 \mathrm{mM} 3$-MA or the two agents simultaneously for 6,24 and $48 \mathrm{~h}$, and the isolated whole cells extracts were subjected to western blot analysis (Fig. 3). Treatment with SFN led to increased protein expression levels of LC3-I and II at 6, 24 and $48 \mathrm{~h}(\mathrm{P}<0.05)$ compared with the SFN-treated cells compared with the control cells. These results suggested the involvement of the autophagic process, since the amount of LC3-II usually correlates well with the number of autophagosomes (16). Simultaneous treatment of SFN with 3-MA also resulted in increased expression levels of the two forms of LC3, compared with the control cells, from as early as $6 \mathrm{~h}$ and the tendency remained unchanged up to $48 \mathrm{~h}$ (Fig. 3A and C; P<0.05). 3-MA treatment alone was used as a control and caused a moderate change in the LC3 protein expression pattern, suggesting that autophagy induction was
A

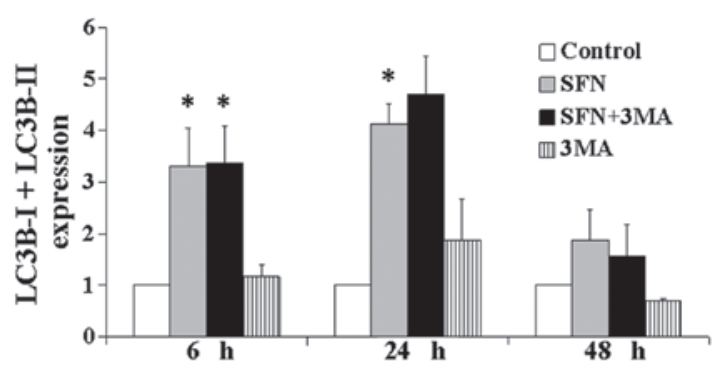

B

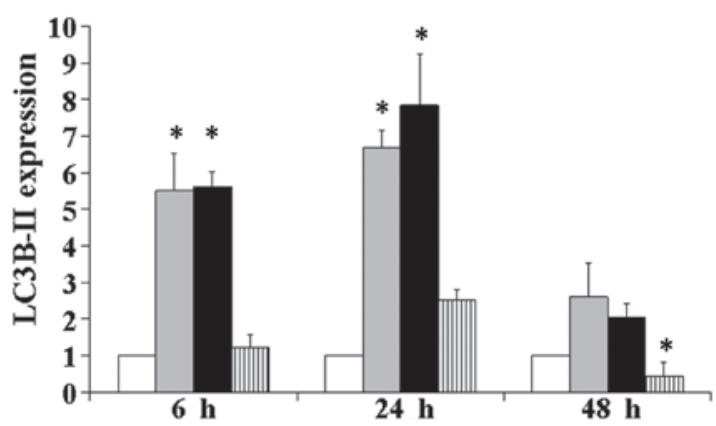

C

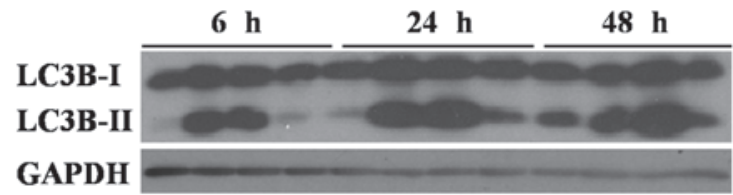

\begin{tabular}{l|c|c|c|c|c|c|c|c||c|c|c|c|}
\multirow{2}{*}{ SFN } & - & + & + & - & - & + & + & - & - & + & + & - \\
\cline { 2 - 10 } 3MA & - & - & + & + & - & - & + & + & - & - & + & + \\
\hline
\end{tabular}

Figure 3. Analysis of the MAP-LC3 marker of autophagy in the BE(2)-C neuroblastoma cell line. The cells were treated wit $40 \mu \mathrm{M}$ SFN, $10 \mathrm{mM} 3-\mathrm{MA}$, or a combination of both. (A) LC3B-I and II, and (B) LC3B-II expression levels were determined. GAPDH protein was used as an internal reference. Three independent experiments were performed and values are presented as the mean \pm standard error of the mean. A series of pairwise t-tests were performed to compare the mean values of the control and treated cells. ${ }^{*} \mathrm{P}<0.05$, compared with the untreated control. (C) Representative western blots. MAP-LC3, microtubule-associated protein light chain $3 \mathrm{SFN}$, sulforaphane; 3-MA, 3-methyladenine; C, untreated control.

almost completely blocked. In addition, microscopic observation of the SFN and 3-MA treated cells suggested that the treatment caused cell death and after $48 \mathrm{~h}$ the cells began to detach from the culture dish (Fig. 1A).

SFN elevates Bax protein expression levels in neuroblastoma cells. In order to further investigate the mechanisms of the observed cell death, the BE(2)-C cells were treated with SFN and 3-MA and the protein expression levels of the antiapoptotic gene Bcl-2 were measured (Fig. 4). After 6, 24 and $48 \mathrm{~h}$ of SFN treatment, the protein expression levels of Bcl-2 remained unchanged. Combined treatment of SFN with 3-MA decreased the protein expression levels of Bcl-2 as compared with SFN treatment alone (Fig. 4A). Treatment with 3-MA alone decreased the Bcl-2 protein expression levels, particularly at $48 \mathrm{~h}$; however this change was not statistically significant. Furthermore, the protein expression levels of another autophagic factor, beclin-1, were measured and shown to remain unchanged following treatment with the agents tested (Fig. 4B). In addition, Bax protein expression levels were evaluated by immunoblotting and increased levels were 
A
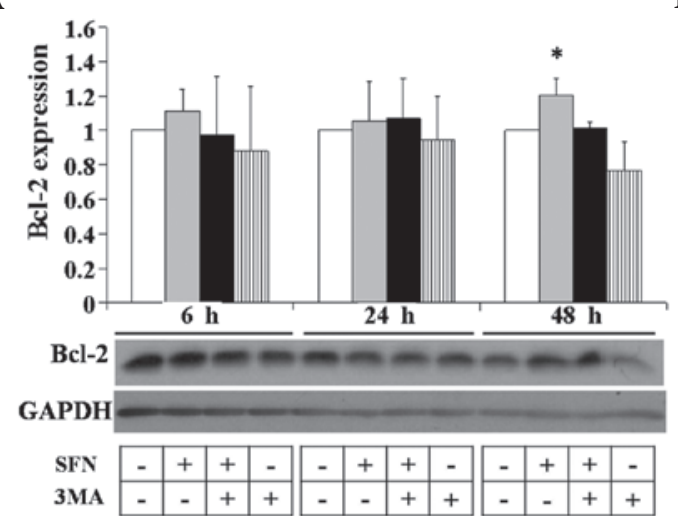

B
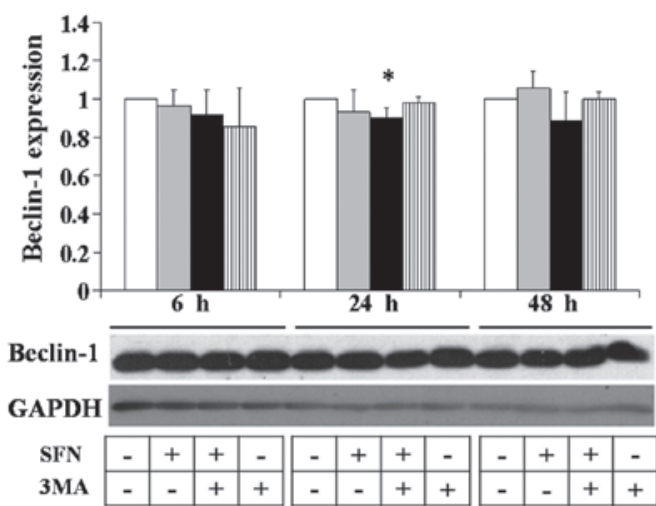

C

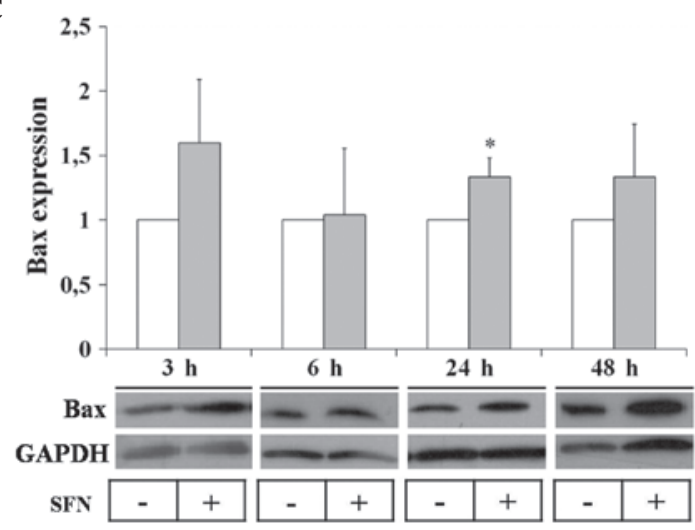

Figure 4. Western blot analysis of Bcl-2, beclin-1 and Bax in the BE(2)-C neuroblastoma cell line. The cells were treated with $40 \mu \mathrm{M}$ SFN, 10 mM 3-MA or a combination of both. Western blot analysis of (A) Bcl-2 protein from three experiments, (B) beclin-1 from three separate experiments and (C) Bax from 2-4 experiments and. GAPDH protein was used as an internal reference. Representative blots are shown. Values are presented as the mean \pm standard error of the mean. A series of pairwise t-tests were performed to compare the mean values, for a given time period, of the treated and untreated control cells. ${ }^{*}<0.05$. BCl-2, B-cell lymphoma 2; Bax, Bcl-2-associated X protein; SFN, sulforaphane; 3-MA, 3-methyladenine.

observed at 6, 24 and $48 \mathrm{~h}$ of SFN treatment (Fig. 4C; $\mathrm{P}<0.05$ ). Changes in the Bax protein levels were statistically significant at $24 \mathrm{~h}$, suggesting the induction of apoptosis.

Analysis of mitochondrial membrane potential in SFN-treated neuroblastoma cells. Flow cytometry was used to measure changes to the mitochondrial membrane potential upon treatment with SFN. CMXRos served as a dye, which actively accumulates in the mitochondria of live cells. Control cells with functional mitochondrial membranes had a high accumulation of CMXRos (Fig. 5A; channel P3). The positive control apoptotic cells had a significant loss in mitochondrial membrane potential and were obtained following treatment with $60 \mu \mathrm{M}$ STS, a known proapoptotic compound, for $24 \mathrm{~h}$ (channel P5). As compared with STS treatment, treatment with $40 \mu \mathrm{M}$ SFN also caused a significant decrease in the mitochondrial membrane potential (Fig. 5A). Treatment with 3-MA alone caused only a minimal decrease in mitochondrial membrane potential, but did not alter the effects of SFN.

In addition, the cells were cultured for 3,6 and $24 \mathrm{~h}$ in the presence of $40 \mu \mathrm{M}$ SFN, $10 \mathrm{mM}$ 3-MA or $60 \mu \mathrm{M}$ STS. No effect was observed on the mitochondrial membrane depolarization in response to treatment with any of the compounds at $3 \mathrm{~h}$ (Fig. 5B), whereas an increase in depolarization was observed in response to STS treatment for $6 \mathrm{~h}$. A significant increase in the number of cells with depolarized mitochondrial membranes was observed in response to treatment with SFN for $24 \mathrm{~h}$ and was comparable with the increase caused by STS and combined treatment of SFN with 3-MA. Treatment with 3-MA alone did not affect mitochondrial membrane depolarization.

\section{Discussion}

The present study aimed to determine how neuroblastoma cells respond to the potential anticancer agent SFN, as well as 3-MA, an inhibitor of autophagy. Naturally occurring isothiocyanates of cruciferous origin have previously been shown to inhibit carcinogenesis $(2,4)$. They may therefore be considered as potential protective and therapeutic agents. Despite intensive treatment, neuroblastoma tumors are difficult to eradicate and $>60 \%$ of children above the age of one year with neuroblastoma have poor prognosis $(24,25)$. Naturally occurring compounds, such as SFN, may be used as a supplementary treatment for cancer therapy, or may be used in combination with conventional therapeutics. It was previously shown that administration of SFN to female rats, through gavage, resulted in a maximum concentration of the compound in the blood and mammary glands as early as at $1 \mathrm{~h}$, reducing the incidence, multiplicity and weight of mammary tumors (1). Therefore, it is likely that the concentration of SFN required to induce cell death may be achievable in humans (7). 
A
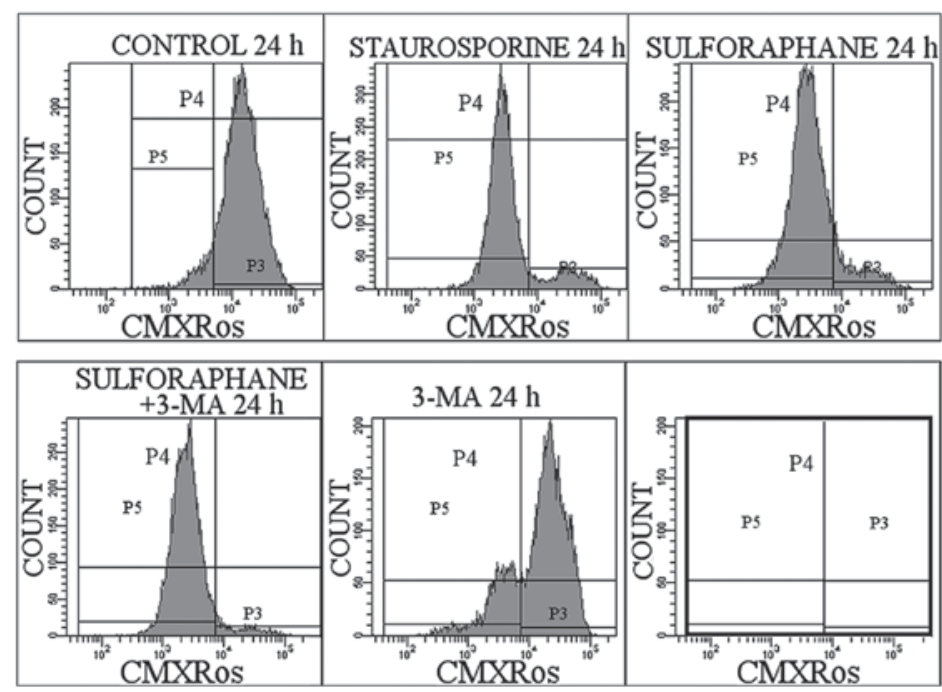

B

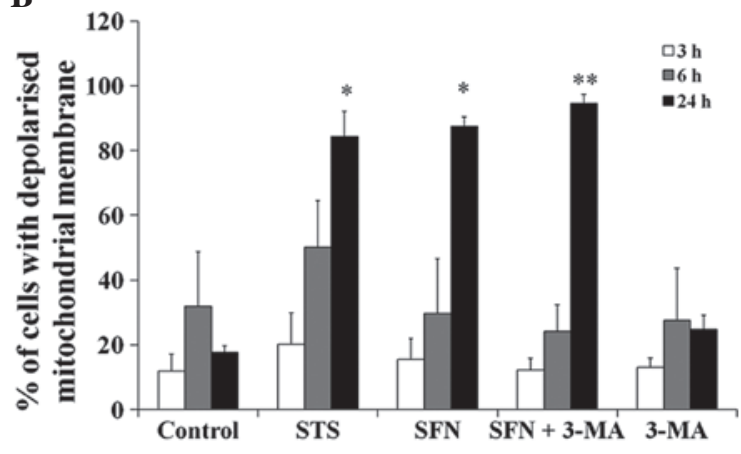

Figure 5. Flow cytometry analysis of the mitochondrial membrane potentials of the cells using CMXRos staining. The BE(2)-C neuroblastoma cells were treated with $40 \mu \mathrm{M}$ SFN, $10 \mathrm{mM} 3-\mathrm{MA}$, a combination of SFN and 3-MA, or $60 \mu \mathrm{M} \mathrm{STS}$. (A) Selected histograms of the BE(2)-C cells following $24 \mathrm{~h}$ of treatment. The analysis was performed by dividing the whole cell population into two groups, with the highest (P3) and the lowest (P5) mitochondrial membrane potential. (B) Effects of SFN and SFN with 3-MA treatment on the BE(2)-C cells after 3, 6 and 24 h. Two separate experiments were performed. Values are expressed as the mean \pm standard error of the mean. A series of pairwise t-tests were performed to compare the means of the treated and untreated control cells. $\mathrm{P}<0.05 ;{ }^{* *} \mathrm{P}<0.01$. SFN, sulforaphane; 3-MA, 3-methyladenine; STS, staurosporine.

In the present study, $40 \mu \mathrm{M}$ SFN induced apoptosis of $\mathrm{BE}(2)-\mathrm{C}$ cells after 24 and $48 \mathrm{~h}$ of treatment, as determined by a decrease in the mitochondrial membrane potential, an increase in caspase activity and inhibition of DNA synthesis. Flow cytometry showed that treatment with SFN decreased the mitochondrial membrane potential in $\sim 40 \%$ of cells at $24 \mathrm{~h}$, and $\sim 62 \%$ of cells at $48 \mathrm{~h}$. Due to its electrophilic nature, SFN may directly modify nucleophilic sites, such as sulfhydryl groups, in mitochondrial respiratory chain enzymes or mitochondrial membranes. Conversely, a previous study reported that apoptosis was inhibited in the PC-3 and LNCaP human prostate cancer cells lines through autophagy induced by treatment with SFN (8). SFN was shown to induce the formation of acidic vesicle organelles, which enclosed whole mitochondria and inhibited apoptosis in the prostate cell lines. Mitochondrial digestion within autophagosomes prevents the leakage of cytochrome $c$ into the cytoplasm and consequently blocks the induction of apoptosis (8). In the present study, SFN induced autophagy and apoptosis, as documented by an increase in LC3II expression levels, as well as caspase activation, an increase in Bax expression levels and loss of mitochondrial membrane potential, respectively. The two forms of LC3, I and II, were increased upon treatment with SFN, and combined treatment with 3-MA resulted in even higher levels at $24 \mathrm{~h}$. Therefore, it may be concluded that SFN causes autophagy by a mechanism independent of autophagy inhibition by 3-MA. However, in the present study, fluorescent fusion methods were not used to determine the protein fate of LC3 within neuroblastoma cells. This method is expected to provide clear evidence of autophagosomal formation.

In the PC-3 prostate cancer cell line, SFN was previously shown to increase the $\mathrm{Bax} / \mathrm{Bcl}-2$ ratio, favoring apoptosis (26). Similar conclusions may be drawn from the results of the present study, as Bax protein expression levels were increased early upon treatment with SFN and remained high at up to $48 \mathrm{~h}$. In addition, in the $\mathrm{BE}(2)-\mathrm{C}$ cells, a negligible change in the protein expression levels of Bcl-2 was observed, thus increasing the Bax/Bcl-2 ratio. Similarly, the lack of stimulatory effects of SFN on Bcl-2 expression levels were demonstrated in a previous study on the Jurkat T-cell lymphoma cell line (6). Beclin-1 interacts with class III PI3K complex and participates in autophagosomal formation $(27,28)$. In the present study, the protein expression levels of beclin-1 remained unchanged in response to treatment with SFN and 3-MA, or a combination of the two, at $6 \mathrm{~h}$. At later time-points, only slight inhibitory effects on the expression levels of beclin-1 were observed in response to combined treatment. These results indicated that beclin-1 was constitutively expressed in the $\mathrm{BE}(2)-\mathrm{C}$ neuroblastoma cells.

Apoptosis and autophagy are precisely regulated and have important roles in the maintenance of homeostasis and disease. Therefore, it is important to distinguish the effects of any potential anti-cancer agent on these two processes. An enhanced understanding of the role of SFN in the induction of cell death may have implications in the design of future clinical trials for combination cancer treatments using SFN and conventional anti-cancer drugs $(24,25)$. The inhibition of autophagy is also an attractive therapeutic approach, since inhibition of autophagy in cancer cells is associated with increased apoptotic cell death $(8,23)$. It has previously been reported that the combination of SFN with autophagy inhibition, by 3-MA or bafilomycin A1, may be a promising strategy for breast cancer (29), human colon cancer (30) or human prostate cancer (8) therapy. Furthermore, the chemopreventive efficacy of SFN may be augmented by inhibition of autophagy using chloroquine in a transgenic adenocarcinoma of mouse prostate as shown in an in vivo study (31). The present study showed that the inhibition of autophagy by 3-MA does not alter 
SFN-induced autophagy and apoptosis in human neuroblastoma cells, although the combined effect of SFN and 3-MA is evidenced by a significant decline in cell viability.

\section{Acknowledgements}

The present study was supported by the Jagiellonian University grant DS/8/WBBiB. The authors acknowledge the help of Dr Aleksandra Kowalczyk in design of the studies and Dr Małgorzata Bzowska for flow cytometric analysis.

\section{References}

1. Fahey JW, Zhang Y and Talalay P: Broccoli sprouts: an exceptionally rich source of inducers of enzymes that protect against chemical carcinogens. Proc Natl Acad Sci USA 94: 10367-10372, 1997.

2. Barcelo S, Gardiner JM, Gescher A and Chipman JK: CYP2E1-mediated mechanism of anti-genotoxicity of the broccoli constituent sulforaphane. Carcinogenesis 17: 277-282, 1996.

3. Brooks JD, Paton VG and Vidanes G: Potent induction of phase 2 enzymes in human prostate cells by sulforaphane. Cancer Epidemiol Biomarkers Prev 10: 949-954, 2001.

4. Tan XL and Spivack SD: Dietary chemoprevention strategies for induction of phase II xenobiotic-metabolizing enzymes in lung carcinogenesis: A review. Lung Cancer 65: 129-137, 2009.

5. Gamet-Payrastre L, Li P, Lumeau S, Cassar G, Dupont MA Chevolleau S, Gasc N, Tulliez J and Tercé F: Sulforaphane, a naturally occurring isothiocyanate, induces cell cycle arrest and apoptosis in HT29 human colon cancer cells. Cancer Res 60 : 1426-1433, 2000.

6. Fimognari C, Nüsse M, Cesari R, Iori R, Cantelli-Forti G and Hrelia P: Growth inhibition, cell-cycle arrest and apoptosis in human T-cell leukemia by the isothiocyanate sulforaphane. Carcinogenesis 23: 581-586, 2002.

7. Singh SV, Srivastava SK, Choi S, Lew KL, Antosiewicz J, Xiao D, Zeng Y, Watkins SC, Johnson CS, Trump DL, Lee YJ, $\mathrm{Xiao} \mathrm{H}$ and Herman-Antosiewicz A: Sulforaphane-induced cell death in human prostate cancer cells is initiated by reactive oxygen species. J Biol Chem 280: 19911-19924, 2005.

8. Herman-Antosiewicz A, Johnson DE and Singh SV: Sulforaphane causes autophagy to inhibit release of cy tochrome $\mathrm{C}$ and apoptosis in human prostate cancer cells. Cancer Res 66: 5828-5835, 2006.

9. Nishikawa T, Tsuno NH, Tsuchiya T, Yoneyama S, Yamada J, Shuno Y, Okaji Y, Tanaka J, Kitayama J, Takahashi K and Nagawa H: Sulforaphane stimulates activation of proapoptotic protein bax leading to apoptosis of endothelial progenitor cells. Ann Surg Oncol 16: 534-543, 2009.

10. Rajendran P, Kidane AI, Yu TW, Dashwood WM, Bisson WH, Löhr CV, Ho E, Williams DE and Dashwood RH: HDAC turnover, CtIP acetylation and dysregulated DNA damage signaling in colon cancer cells treated with sulforaphane and related dietary isothiocyanates. Epigenetics 8: 612-623, 2013.

11. Xiao D, Powolny AA, Antosiewicz J, Hahm ER, Bommareddy A, Zeng Y, Desai D, Amin S, Herman-Antosiewicz A and Singh SV: Cellular responses to cancer chemopreventive agent $\mathrm{D}, \mathrm{L}$-sulforaphane in human prostate cancer cells are initiated by mitochondrial reactive oxygen species. Pharm Res 26: 1729-1738, 2009.
12. Klionsky DJ: Autophagy: from phenomenology to molecular understanding in less than a decade. Nat Rev Mol Cell Biol 8: 931-937, 2007.

13. Tsuchihara K, Fujii S and Esumi H: Autophagy and cancer: dynamism of the metabolism of tumor cells and tissues. Cancer Lett 278: 130-138, 2009

14. Pattingre S, Tassa A, Qu X, Garuti R, Liang XH, Mizushima N, Packer M, Schneider MD and Levine B: Bcl-2 antiapoptotic proteins inhibit Beclin 1-dependent autophagy. Cell 122: 927-939, 2005.

15. Meijer AJ and Codogno P: Regulation and role of autophagy in mammalian cells. Int J Biochem Cell Biol 36: 2445-2462, 2004.

16. Mizushima N, Yoshimori T and Levine B: Methods in mammalian autophagy research. Cell 140: 313-326, 2010.

17. Giménez-Xavier P, Francisco R, Santidrián AF, Gil J and Ambrosio S: Effects of dopamine on LC3-II activation as a marker of autophagy in a neuroblastoma cell model. Neurotoxicology 30 : 658-665, 2009.

18. Schmidt H and Karrer P: Synthese der recemischen und der optisch aktiven formen des sulforaphans. Helv Chim Acta 31: 1067-1074, 1948 (In German).

19. Denizot F and Lang R: Rapid colorimetric assay for cell growth and survival. Modifications to the tetrazolium dye procedure giving improved sensitivity and reliability. J Immunol Methods 89: 271-277, 1986.

20. Riss TL and Sirbasku DA: Growth and continuous passage of COMMA-D mouse mammary epithelial cells in hormonally defined serum-free medium. Cancer Res 47: 3776-3782, 1987.

21. Sadowski HB, Shuai K, Darnell JE Jr and Gilman MZ: A common nuclear signal transduction pathway activated by growth factor and cytokine receptors. Science 261: 1739-1744, 1993.

22. Myzak MC and Dashwood RH: Chemoprotection by sulforaphane: keep one eye beyond Keap1. Cancer Lett 233: 208-218, 2006.

23. Livesey KM, Tang D, Zeh HJ and Lotze MT: Autophagy inhibition in combination cancer teatment. Curr Opin Investig Drugs 10: 1269-1279, 2009.

24. Brodeur GM: Neuroblastoma: biological insights into a clinical enigma. Nat Rev Cancer 3: 203-216, 2003.

25. Maris JM,Hogarty MD, Bagatell R and Cohn SL: Neuroblastoma. Lancet 369: 2106-2120, 2007

26. Singh AV, Xiao D, Lew KL, Dhir R and Singh SV: Sulforaphane induces caspase-mediated apoptosis in cultured PC-3 human prostate cancer cells and retards growth of PC-3 xenografts in vivo. Carcinogenesis 25: 83-90, 2004.

27. Levine B and Klionsky DJ: Development by self-digestion: molecular mechanisms and biological functions of autophagy. Dev Cell 6: 463-477, 2004.

28. Zhao L, Zhu Y, Wang D, Chen M, Gao P, Xiao W, Rao G, Wang X, Jin H, Sui N and Chen Q: Morphine induces Beclin-1 and ATG5-dependent autophagy in human neuroblastoma SH-SY5Y cells and in the rat hippocampus. Autophagy 6: 386-394, 2010.

29. Kanematsu S, Uehara N, Miki H, Yoshizawa K, Kawanaka A, Yuri $\mathrm{T}$ and Tsubura A: Autophagy inhibition enhances sulforaphane-induced apoptosis in human breast cancer cells. Anticancer Res 30: 3381-3390, 2010.

30. Nishikawa T, Tsuno NH, Okaji Y, Shuno Y, Sasaki K, Hongo K, Sunami E, Kitayama J, Takahashi K and Nagawa H: Inhibition of autophagy potentiates sulforaphane-induced apoptosis in human colon cancer cells. Ann Surg Oncol 17: 592-602, 2010.

31. Vyas AR, Hahm E-R, Arlotti JA, Watkins S, Stolz DB, Desai D, Amin S and Singh SV: Chemoprevention of prostate cancer by d,l-sulforaphane is augmented by pharmacological inhibition of autophagy. Cancer Res 73: 5985-5995, 2013. 